\title{
Teaching Accounting For Inventory By Calling On Students' Personal Experiences
}

John Briginshaw, Pepperdine University, USA

\begin{abstract}
This essay seeks to give practical guidance to accounting instructors seeking to convey the difficult concepts of accounting for inventory. Techniques to convey the concepts of assumed inventory flow, inventory valuation under inflation and deflation, impairment of inventories, LIFO liquidations and the concept of the periodic inventory system are considered.
\end{abstract}

Keywords: accounting, inventory, LIFO, FIFO, flow, valuation, liquidation, periodic, perpetual, LCM

\section{INTRODUCTION}

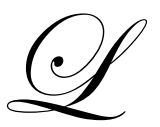

aux (2007) gives a valuable summary of the theoretical issues involved in accounting for inventory. This paper seeks to complement that work by proposing some methods of teaching inventory that seek to maximize student involvement and learning by calling on student's personal experiences. In order to do this, the retail business (one that students have everyday experience of) is extensively used in the discussion. This is despite the fact that experience of this industry, especially its extensive use of barcode scanning technology, may sometimes lead students to the conception that the inventory flow assumptions that underlie GAAP treatment of inventory may "not be needed anymore". The preconception can be directly addressed and corrected by carefully conveying the accounting concepts in the context of the underlying business environment.

First, some key accounting concepts are listed (in Table 1) that instructors may wish to convey in an initial class or lecture on accounting for inventory. Professors may wish to choose a subset or superset of these concepts, but to show them here is intended to set expectations as to what may be achieved.

Table 1: Concepts to be Conveyed

- Inventory valuation in GAAP: value = physical count multiplied by approximate price

- Inventory flow assumptions: LIFO (Last in first out) vs. FIFO (First in first out)

- Irrelevance of physical flow

- Reasons for selecting a method: nature of business, financial (especially tax) effects, impact of inflation

- $\quad$ Other inventory valuation issues

- $\quad$ Lower of cost or market rule

- $\quad$ Concept of LIFO liquidation

- Periodic vs Perpetual systems

- $\quad$ Administrative savings

- $\quad$ Treatment of shrinkage

- Usefulness of POS systems in a periodic system

\section{ESTABLISHING THE NEED FOR ASSUMED INVENTORY FLOW}

The concept of assumed inventory cost flow will be introduced by using two sample businesses, selected to exemplify LIFO and FIFO usage. However, the preconception of students, who are exposed to point of sale (POS) bar code scanners in their everyday lives, is that outgoing inventory is tracked at point of sale and that this tracking process can be used to calculate cost of goods sold (COGS) - i.e. that there is no need to approximate in determining which inventory has flowed out. This preconception may be challenged in three ways. 
1. Barcode based POS scanners do not provide sufficient detail to calculate the historical cost of the specific items which are sold, because the bar code of a given product does not vary according to when it was delivered or what wholesale cost prevailed on that date.

2. Accepting bar code scanner records as the cost of goods sold would lead to shrinkage being ignored and excluded from COGS, as stolen or spoiled goods do not pass through the POS scanners.

3. Smaller businesses do not have access to bar code scanners (although as the price of scanning technology decreases, this argument is less and less effective)

Therefore, as a suggested first step in the presentation, instructors may wish to note why the use of assumed cost flow is necessary, by stating that:

1. Dollar value of inventory is calculated as number of units, $q$ (or $n)$, multiplied by price per unit, $p$

2. While GAAP usually requires a physical count of inventory, $q$, it allows price, $p$, to be approximated, for example by using the price of the oldest q units (LIFO) or the newest q units (FIFO) for the ending inventory

3. If this approximation was not allowed, companies would have a difficult task in tracking not just what product (e.g. 20 ounce box of cornflakes) has been sold, but precisely when the product arrived (e.g. one of the 12 boxes of cornflakes that arrived on Feb 23) in order to determine the supplier's price. Bar codes do not allow this level of tracking (although RFID (Radio Frequency Identification) chip technology may do so in the future).

This makes use of argument 1 listed above, however the other 2 arguments may also be marshaled. If not, argument 2 is introduced later in discussing the periodic inventory concept. To underscore these arguments, instructors may refer to the empirical findings of AICPA (2005) (quoted in Needles et al (2008) pp. 354) showing that FIFO, LIFO and average cost (approximated methods of tracking inventory flow) are dominant, with respectively $64 \%, 40 \%$ and $28 \%$ of companies using these methods for some or all of their inventory - while $5 \%$ of firms use any other method (which includes methods where individual units are tracked, i.e. the "specific identification method" or SPIM). The instructor's task is sometimes complicated by the inclusion of SPIM as an alternative method in text book problems - it should be pointed out that SPIM is included in textbook problems as it is an "ideal" method. In practice, tracking individual units is too costly in its use of staff and management time. The fact that the sum of the usage figures exceeds $100 \%$ (implying that multiple inventory methods are used by some companies) provides an opportunity to introduce the issue that outside the US, LIFO is not usually permitted (meaning multinationals making use of LIFO in the USA must also use FIFO for their international operations). This issue is developed further in the section on LIFO liquidations, later in the paper.

\section{CONVEYING THE CONCEPT OF ASSUMED INVENTORY FLOW}

In order to convey how assumed cost flow helps businesses, two sample businesses are proposed. Firstly, a single-person store selling a non-perishable good such as fertilizer (LIFO). Secondly, a larger retailer selling a highly perishable good, such as milk (FIFO).

The fertilizer store can be imagined as a storeroom where purchases of inventory are stacked at the back of the room, with new inventory is placed in front of the old inventory. Given the non-perishable nature of the product (provided it is kept dry), customers will simply take the most accessible bags of fertilizer at the front, which happen to be the newest (LIFO). The fertilizer store, after the purchase of two batches of four bags of fertilizer, priced respectively at $\$ 100$ and $\$ 110$ per bag, could be depicted on the whiteboard as shown in Figure 1.

A customer buying two bags will typically take two bags from the front row, thus making a LIFO assumption reasonable (and fixing the cost of the physical bags sold as \$220, equal to the COGS under the LIFO assumption). The fact that a LIFO assumption has been made should be stressed to students. However, if the customer insists on taking the two rightmost bags (one from the older and one from the newer batch), what would be the COGS for those two bags, under the LIFO assumption? The cost must still be $\$ 220$, irrespective of which bags have been taken. If LIFO is not assumed but is seen as a guideline on what "usually happens", the administrative workload of tracking individual bags would still be incurred. 
Figure 1: Schematic of Fertilizer Store to Illustrate LIFO Inventory Flow

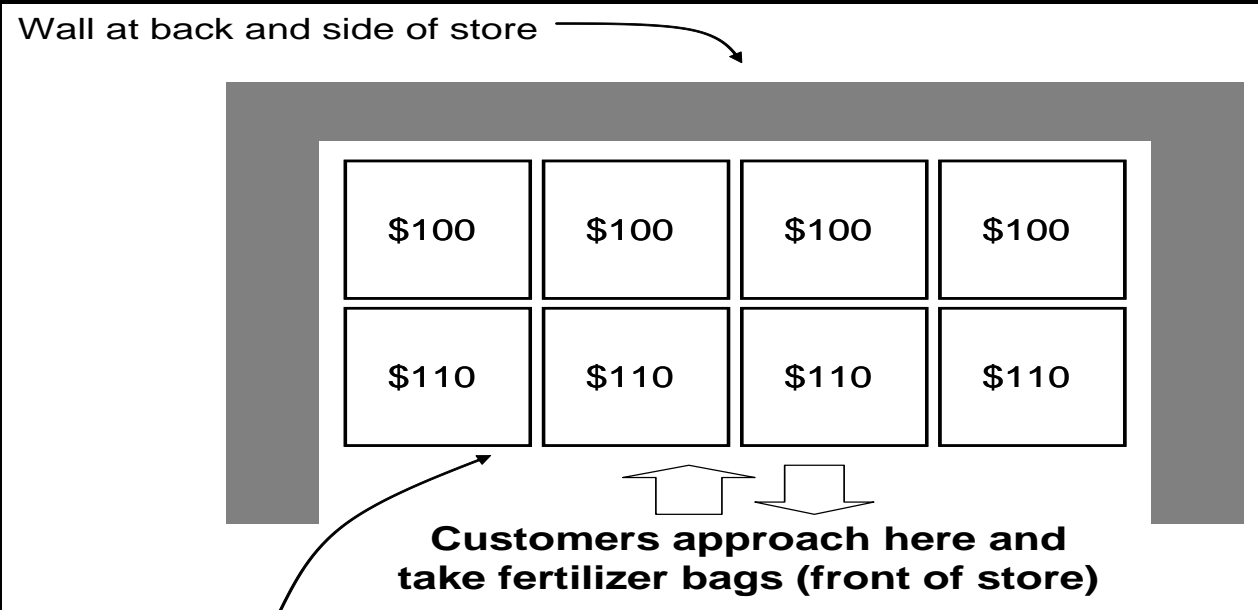

Bags of fertilizer, labeled with the

original purchase price of each bag

The second example is a food retail store or supermarket selling milk (instructors should name the store as a local food store, such as Albertson's (Supervalu) in Southern California or Giant in Maryland, Virginia or DC). The first inventory of 4 cartons of milk is purchased for $\$ 1$ and a second batch of 4 cartons at $\$ 1.10$. Students might be asked how the milk would be stacked in the refrigerator - usually with the newest milk at the back to encourage customers to buy the older milk first, thus justifying the FIFO assumption. The milk refrigerator, with the inventory of 8 cartons, might be depicted on the whiteboard as shown in Figure 2.

Figure 2: Schematic of Milk Refrigerator to Illustrate FIFO Inventory Flow

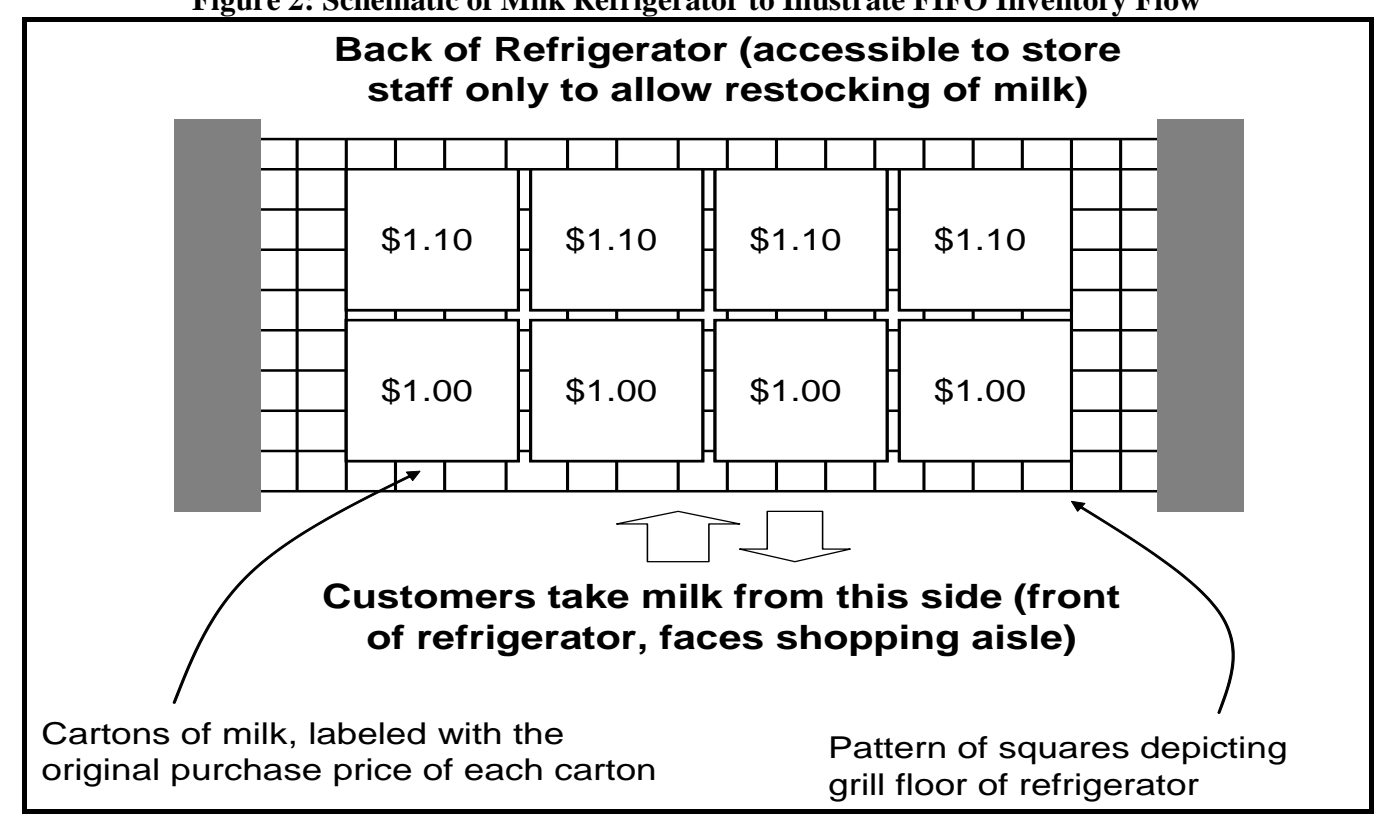

The supermarket will hope that a typical customer purchasing 2 cartons of milk will take the milk at the front, and that the "true" COGS will be $\$ 2.00$, in accordance with the assumed FIFO flow. Then students can be asked how they select cartons if they are buying 2 cartons of milk - often they will state that they will try and secure 
the newest milk at the back of the refrigerator. However, what then should be the COGS under the FIFO assumption? As FIFO is only an assumption, the answer should be $\$ 2.00 .^{1}$

\section{INVENTORY VALUATION: LCM (LOWER OF COST OR MARKET) RULE}

Discussion of older milk leads naturally into the subject area of impairment of inventory, which may be covered as a brief sidebar. The detailed application of the LCM rule is a complex area that instructors may or may not want to cover in depth. A simple example of spoiled milk (zero market value, unless one is an amateur cheese maker) can illustrate the concept at a basic level, by showing the effect of the necessary write-off on the inventory asset and on the income statement, usually via COGS. If time and student aptitude allows, a more detailed example using replacement cost may be shown, illustrating the effects if a fall in the wholesale price for milk. For advanced classes, instructors may discuss the upper bound on cost of net realizable value (NRV, defined by GAAP as selling price less costs to complete) and the lower bound of NRV minus typical profit margin.

\section{FINANCIAL EFFECT OF INVENTORY FLOW ASSUMPTIONS AND THE LIFO LIQUIDATION PROBLEM}

Since the pricing within the two stores has been set up to be different by a factor of one hundred ( $\$ 100 \mathrm{vs}$ $100 \notin$ for the older inventory, $\$ 110$ and $110 \notin$ for the newer inventory), students may be able to draw some conclusions from the different relative values of COGS for the two sales of 2 units each. Both the fertilizer and milk markets have experienced inflation, and students may be asked to confirm that this is the normal pattern in the US economy. The COGS of the LIFO example (fertilizer) is higher (relatively speaking) than that of the FIFO example (milk), and this is typical in an inflationary environment ${ }^{2}$. At this stage the use of the FIFO COGS appears sensible in maximizing earnings. The issue of tax and the LIFO conformity rule should then be introduced, as a reason why companies frequently seek to use LIFO. The uniqueness of the LIFO conformity rule should be emphasized, as otherwise this one example of forced congruence between tax and financial accounting may lead to misconceptions among students. This has the potential to be damaging to their future studies, since financial accounting decisions are not usually dependent on tax accounting.

To illustrate how important the tax issues for LIFO can be, instructors may return to the example of the fertilizer store. Suppose, the manager has sold all of his or her inventory by Dec $28^{\text {th }}$ (COGS of $\$ 840$ ), and perhaps is going skiing. But he or she receives a phone call from his or her accountant with instructions to buy 8 more bags of fertilizer, now priced at $\$ 120$, before the December 31 reporting date. Why might the accountant be saying this? Instructors can "stock" the fertilizer store with the new $\$ 120$ bags (on the whiteboard), and then ask students - what is the newest inventory at December 31? The inventory just bought. And so, what should be the (LIFO) COGS? (\$960) Then, since the IRS accepts this LIFO COGS, how much tax is saved? (slightly more than $\$ 40$ at a 35\% corporate tax rate, since COGS is $\$ 120$ higher and therefore accounting and taxable income is $\$ 120$ lower). What the fertilizer store has done is avoid a LIFO liquidation, and it has therefore saved tax.

Students may understand intuitively that this causes a low value of ending inventory (despite the physical ending inventory consisting of the most expensive bags), since what is not sold (and included in COGS) must remain in ending inventory. Thus the fertilizer store manager must be wary to avoid LIFO liquidations in each following year, or face increased tax liability as the sale of his "cheap" inventory is recognized. The manager's potential additional profit in the future (should he or she liquidate all of the inventory) is the same $\$ 120$ as was avoided by the end of year purchase. This dollar figure is termed the "LIFO reserve" and is also equal to the difference between the cost of the physical ending inventory and the (lower) accounting cost of the ending

\footnotetext{
${ }^{1}$ Students may ask, given the behavior of some customers in seeking the newest milk, whether FIFO is reasonable, and whether LIFO should be used for milk (although, in the author's experience, they do not ask this). Instructors may then mention the need to achieve realistic valuation of ending inventory. Ending inventory valuation is always a weakness of LIFO (the strength of which is that it determines a COGS close to current (i.e. replacement) cost), but assigning a positive value to years' old milk would be absurd. If not introduced here, the issue of ending inventory valuation under LIFO is covered during the discussion of LIFO liquidation.

${ }^{2}$ At this point instructors may also mention that the average cost method give a COGS somewhere in between that of LIFO and FIFO and that the SPIM COGS is bounded below by the FIFO COGS and bounded above by the LIFO COGS.
} 
inventory. Focusing on a non-accounting issue, some students may question whether it is worth paying a high price for the inventory at the end of the year in order to avoid $\$ 40$ of tax. If the $\$ 120$ is a result of a temporary spike in price, it may indeed be better for the fertilizer store to wait if the premium to get delivery before the end of the year exceeds the tax savings. However, the store will probably need to restock in early January anyway and, if prices will be similar at that time, then the case for buying before the balance sheet date is clear.

At this stage the instructor may wish to touch on the large potential effects of LIFO liquidation on some industrial companies which have used LIFO for a long period of time. Easton et al (2010) (pp. 6-19) note the example of Caterpillar, which reports inventories on its 2007 balance sheet (using LIFO) which are some \$2.6bn below what they would be if FIFO was to be used (i.e. \$2.6bn is the LIFO reserve). If Caterpillar were to sell all of this "low cost" inventory (which is only low cost because units in the balance sheet inventory date back several years; also, the units may not correspond to the physical inventory Caterpillar possesses), the company would see an additional profit of $\$ 2.6 \mathrm{bn}$ and an additional tax bill of approximately $\$ 1 \mathrm{bn}$. An even more extreme example is noted by Hoffman and MacKenzie (2009): Exxon's \$25.4bn 2007 LIFO reserve could increase its taxes payable by as much as $\$ 9 \mathrm{bn}$ if this low cost inventory were to be sold (or to be treated as sold for accounting purposes). Since IFRS does not permit LIFO, instructors may take the opportunity to discuss the possible introduction of IFRS to the United States and the possible effects of introduction on businesses which use the LIFO method (see White (2009) and Briginshaw (2008)). Another potential area for discussion is the complexity of accounting for the levels of inventory within LIFO, and the associated recordkeeping. The LIFO reserve, because of its relevance to financial analysis, can be a profitable topic to consider at the MBA level; that of LIFO layers lends itself more to the undergraduate major audience.

Having discussed the effects of the LIFO assumption in depressing income, instructors may choose to explore whether there are any industries where the pattern would not hold. Students will usually volunteer the technology or computer industry as industries where components tend to decline in price over time (deflation). Therefore, FIFO would give the higher COGS in this case.

\section{PERIODIC INVENTORY SYSTEM VS PERPETUAL INVENTORY SYSTEM}

The instructor may choose to introduce the use of the periodic inventory system earlier in the discussion, and this can work well. The chief argument for delaying until the end of the inventory topic is that the calculations of the COGS in the fertilizer and milk examples are, strictly speaking, predicated on the perpetual inventory model. In a periodic inventory system, neither COGS nor ending inventory are determined until the end of the period.

Instructors may note some basic features of the perpetual inventory system, especially that companies using the perpetual system update their inventory asset when purchases and sales occur, and take regular physical counts of inventory. This leads to a closer tracking of inventory than the periodic system, where inventory is only updated in the accounting records once per period. A brief discussion about which companies and products a perpetual inventory system may be best suited for can then be carried out - for example, high value products. By the process of contrasting high value with low value products, the suitability of the periodic inventory system for the two examples above (fertilizer and food retail) can be noted, and either can be used as an illustrative example in the discussion below. The supermarket example is recommended, as otherwise students may be left with the belief that the conclusions are not valid for businesses with barcode scanning at POS.

The periodic inventory system, and its indirect determination of COGS, can be introduced by reasoning that ending inventory $\left(\mathrm{I}_{1}\right)$ can be calculated as beginning inventory $\left(\mathrm{I}_{0}\right)$, plus inventory added (purchases) minus inventory taken away (COGS). The intuition of this equation may be more attractive to students than jumping straight into the standard format for calculating COGS. In equation form:-

$\mathrm{I}_{1}=\mathrm{I}_{0}+$ purchases - COGS

Appealing to students' high school math, since there is one equation, it can be solved even if one variable is unknown. The necessity of a physical count at each year-end having been previously mentioned (meaning that $\mathrm{I}_{0}$ and $I_{1}$ must be measured), either purchases or COGS will be the unknown, the other variable being observed. The 
next question is: which of these two should be observed (counted) and which left as the unknown (calculated), in order to minimize administrative costs? This question has to be carefully framed, because such is students' trust in the bar-coding and POS technologies that they see in their daily lives, they are apt to say that it is purchases that should be left as the unknown. Instructors are advised to adopt a two stage approach to asking this question. Firstly, how often are milk or cornflakes delivered to the supermarket? Once or twice per week - 52 or 104 times per year. And how many times do customers walk out with one or two cartons of milk or boxes of cornflakes? Clearly, dozens or hundreds of times per day. Structured in this way, it becomes clear to students that the administrative effort of tracking purchases is trivial compared to that of tracking sales, and that COGS should be left as the unknown, and calculated from the other data. It is then a simple task to demonstrate the solution for COGS:-

COGS $=\mathrm{I}_{0}+$ purchases $-\mathrm{I}_{1}$

and then to relate this to the standard format of the income statement, where the subtotal "Cost of Goods available for sale" is often calculated as $\mathrm{I}_{0}+$ purchases.

Interesting questions may then be asked by students. For example: What is the point of having the bar coding systems if a company is using the periodic system? And, more penetratingly, what happens to shoplifted or stolen product in the periodic system? COGS has been determined based on the inventory which has left the store, irrespective of whether it has been paid for - stolen goods have been "lumped into" COGS, together with goods actually purchased! The instructor should point out that this approach is sensible, far more sensible than determining COGS using the output of the POS scanners, since the periodic system ensures shrinkage costs are expensed (as part of COGS), whereas the POS scanners cannot detect shrinkage at all. Students can then better appreciate the incremental value that the POS scanners do provide to retailers. The difference between the accounting COGS determined by the periodic system, and the record of goods sold from the POS scanners can provide an estimate of shrinkage which, although not broken out in the financial statements, may be used as a performance measure for store management. Finally, the POS scanners can help management calculate a useful approximate value of inventory remaining, in the interim between the physical counts mandated by GAAP. Presented in this way, the persistence of the periodic inventory system alongside the high technology of the barcode scanner is easier for students to understand. It is fair to note, however, that the introduction of POS scanners has increased the ease of adopting a perpetual inventory system, for firms that wish to do so (Needles et al (2008) pp. 290).

\section{CONCLUSION}

This article surveyed the list of concepts that may be conveyed in a lecture giving students their first exposure to accounting for inventory. The article then explored the retail industry as an attractive sample industry to motivate discussions of how physical inventory flow and accounting inventory flow based on the LIFO or FIFO assumptions can be different from each other. Ways to motivate the LIFO tax benefit and LIFO liquidation issues were also discussed, together with the benefits that POS scanners provide to retailers, even if those retailers use a periodic inventory system. By involving students in the discussion based on their own shopping behavior, these ways of discussing inventory accounting may facilitate learning and retention.

\section{AUTHOR INFORMATION}

John Briginshaw, $\mathrm{PhD}$, is an assistant professor of Accounting at the Graziadio School of Business and Management of Pepperdine University. He has business experience in the shipping industry and management consulting experience in the retail banking, garment, and fast-moving consumer goods sectors. He has teaching experience at London Business School and University of California, Berkeley, as well as executive training experience at Euromoney Training, London and Hong Kong. Dr. Briginshaw is the author of Internet Valuation, published by Palgrave MacMillan. He received his MBA from the London Business School and a PhD from the University of California, Berkeley. 


\section{REFERENCES}

1. AICPA (2005). Accounting Trends and Techniques $\left(59^{\text {th }}\right.$ edition). AICPA (New York, NY).

2. Briginshaw, John (2008). What Will The International Financial Reporting Standards (IFRS) Mean to Businesses and Investors? Graziadio Business Report, 11 (4).

3. Easton, Peter D., Robert F. Halsey, Mary Lea McAnally, Al L. Hartgraves and Wayne J. Morse (2010). Financial and Managerial Accounting for MBAs ( $2^{\text {nd }}$ edition). Cambridge Business Publishers (Westmont, IL).

4. Hoffman, Michael J. R. and Karen S. McKenzie (2009). Must LIFO Go to Make Way for IFRS? The Tax Adviser, 40 (March 2009) 156-161

5. Laux, Judith A. (2007). Accounting Issues: An Essay Series Part III-Inventory. Journal of College Teaching \& Learning. 4 (8) 1-6.

6. Needles, Belverd E., Marian Powers and Susan V. Crosson (2008). Financial and Managerial Accounting ( $8^{\text {th }}$ edition). Houghton Mifflin (Boston, MA).

7. White, George (2009). LIFO and IFRS: How Closely Linked? Tax Notes (June 2009). Available: http://www.taxanalysts.com/www/features.nsf/Articles/A6EBC0C7B01F8766852575EF0062BF $\underline{\text { 53?OpenDocument }}$ 
NOTES 